\title{
Influence of diabetes on short-term outcome after major hepatectomy: an underestimated risk?
}

\author{
Alexander Fischer ${ }^{1 \dagger}$, Juri Fuchs ${ }^{1 \dagger}$, Christos Stravodimos ${ }^{2}$, Ulf Hinz ${ }^{1}$, Adrian Billeter ${ }^{1}$, Markus W. Büchler ${ }^{1}$, \\ Arianeb Mehrabi ${ }^{1}$ and Katrin Hoffmann ${ }^{1 *}$
}

\begin{abstract}
Background: Patient-related risk factors such as diabetes mellitus and obesity are increasing in western countries. At the same time the indications for liver resection in both benign and malignant diseases have been significantly extended in recent years. Major liver resection is performed more frequently in a patient population of old age, comorbidity and high rates of neoadjuvant chemotherapy. The aim of this study was to evaluate whether diabetes mellitus, obesity and overweight are risk factors for the short-term post-operative outcome after major liver resection.

Methods: Four hundred seventeen major liver resections ( $\geq 3$ segments) were selected from a prospective database. Exclusion criteria were prior liver resection in patient's history and synchronous major intra-abdominal procedures. Overweight was defined as $\mathrm{BMI} \geq 25 \mathrm{~kg} / \mathrm{m}^{2}$ and $<30 \mathrm{~kg} / \mathrm{m}^{2}$ and obesity as $\mathrm{BMI} \geq 30 \mathrm{~kg} / \mathrm{m}^{2}$. Primary end point was 90 -day mortality and logistic regression was used for multivariate analysis. Secondary end points included morbidity, complications according to Clavien-Dindo classification, unplanned readmission, bile leakage, and liver failure. Morbidity was defined as occurrence of a post-operative complication during hospital stay or within 90 days postoperatively.

Results: Fifty-nine patients had diabetes mellitus (14.1\%), 48 were obese (11.6\%) and 147 were overweight (35.5\%). There were no statistically significant differences in mortality rates between the groups. In the multivariate analysis, diabetes was an independent predictor of morbidity $(\mathrm{OR}=2.44, \mathrm{p}=0.02)$, Clavien-Dindo grade IV complications $(\mathrm{OR}=3.6, \mathrm{p}=0.004)$, unplanned readmission $(\mathrm{OR}=2.44, \mathrm{p}=0.04)$ and bile leakage $(\mathrm{OR}=2.06, \mathrm{p}=0.046)$. Obese and overweight patients did not have an impaired post-operative outcome compared patients with normal weight.

Conclusions: Diabetes has direct influence on the short-term postoperative outcome with an increased risk of morbidity but not mortality. Preoperative identification of high-risk patients will potentially decrease complication rates and allow for individual patient counseling as part of a shared decision-making process. For obese and overweight patients, major liver resection is a safe procedure.
\end{abstract}

Keywords: Major hepatectomy, Risk factors in liver surgery, Diabetes in liver surgery, Overweight in liver resection, Metabolism, Liver resection, Liver cancer, Liver metastasis

*Correspondence: katrin.hoffmann@med.uni-heidelberg.de

${ }^{\dagger}$ Alexander Fischer and Juri Fuchs share first-authorship for this article

1 Department of General and Transplant Surgery, University Hospital

Heidelberg, Ruprecht-Karls-University, Im Neuenheimer Feld 110,

69120 Heidelberg, Germany

Full list of author information is available at the end of the article

\section{Background}

The indication for liver resection has been expanded significantly in recent years. Simultaneously, the operation's safety and efficacy have improved [1-6]. Nowadays, increasing proportions of patients with advanced age, neo-adjuvant treatment and associated comorbidities 
undergo even extended liver resections [6, 7]. Complex liver resection with concomitant biliary or vascular resection is a standard surgical procedure as part of a multi-disciplinary treatment approach [6]. However, major hepatectomy has been associated with a higher risk of post-operative mortality, morbidity, and higher rates of post-hepatectomy liver failure (PHLF) [8-11]. In the latter, the quality of the parenchyma within the future liver remnant has a crucial influence on the postoperative outcome. With the tremendous increase of diabetes mellitus [12], obesity and overweight [13] during the last decades a new group of patients with parenchymal disorders within the liver gets into focus of liver surgeons. The prevalence of diabetes and obesity in the adult population have reached values of $13 \%$ [14] and 37\% [15] in the United States. Recent data clearly show that diabetes and obesity are frequently associated with non-alcoholic fatty liver disease (NAFLD) $[16,17]$ and may also be predictors for progression to fibrosis and cirrhosis $[18,19]$. NAFLD was found to be associated with higher rates of postoperative mortality [20, 21], morbidity [21], PHLF [22] as well as infectious complications [23] after liver resection. However, influence of diabetes and obesity on the outcome after major liver resection is discussed controversially. While some authors showed higher rates of major complications in obese patients after major liver resection $[17,24]$ and higher mortality rates in morbidly obese patients after liver resection [25], others could not confirm those findings [26-29]. The evidence for the influence of diabetes on the outcome after liver resection is even weaker. Few studies have reported on the effect of diabetes on mortality after major liver resection [30, 31]. Here, the results were heterogeneous, too. Nevertheless, sometimes smaller centers even discourage diabetic and obese patients from potentially life-saving major liver resections out of fear of fatal outcomes. An accurate assessment of the safety of major liver resections by clearcut definition of risk groups will enable those surgeons to provide appropriate counseling to their patients within a shared decision-making process. The 90-day mortality rate as well as classification of complications according to Clavien-Dindo [32] and the unplanned readmission rate are broadly accepted reliable surrogates for the shortterm outcome after hepatectomy [26,33-35].

Aim of the study was to evaluate the influence of diabetes mellitus, obesity and overweight on the short-term outcome after major hepatectomy.

\section{Methods}

All patients undergoing major hepatectomy were considered for inclusion. The prospective liver resection database of the institution represented more than $99 \%$ of all performed liver resections of the department. Additional information was acquired retrospectively from the patient files and missing data on the postoperative course were obtained by contacting the patients, physicians or registration offices. Patients younger than 18 years of age, patients with antecedent liver resection, with insitu split or laparoscopic resection, with liver resections performed simultaneously with other operations (such as pancreaticoduodenectomy, the unroofing of simple or parasitic cysts, cystectomy, and necrosectomy) as well as patients with hepatobiliary trauma or resection after liver transplantation were excluded from the analysis. Major liver resection was defined as resection of three or more Couinaud segments and the extent of liver resection was described according to the Brisbane 2000 system [36, 37]. Analysis of the data was approved by the ethical review committee of the University of Heidelberg (07/2013).

The indication for surgical treatment was confirmed by a multidisciplinary team by evaluation of each individual case within the weekly liver surgery tumor board. The extent of surgery depended on the preoperative presumptive diagnosis, the extent of tumor, the liver function, and other factors. In dependence of the characteristics of the parenchyma and the preference of the surgeon the liver parenchyma was transected using the vascular stapler, LigaSure $^{\mathrm{TM}}$, clamp-crushing technique or Cavitron Ultrasonic Surgical Aspirator (CUSA). Portal triad clamping and selective inflow occlusion were performed as necessary in a minority of procedures. The central venous pressure was reduced to $\leq 5 \mathrm{mmHg}$ during the parenchymal transection.

According to their body mass index (BMI), patients were divided into the following groups, which represent a modification of the WHO classification [38]: Underweight $<18.5, \quad 18.5 \leq$ normal $\quad$ weight $<25, \quad 25 \leq$ overweight $<30$, obesity $\geq 30$, and morbid obesity $\geq 35 \mathrm{~kg} /$ $\mathrm{m}^{2}$. Data on diabetes mellitus and other comorbidities were based on diagnoses reported in the health record after thorough preoperative exploration. Diabetes mellitus included diabetes mellitus type 1 as well as type 2 . The laboratory results, that were as close as possible to the date of surgery, but not older than 30 days were registered. Tumor diagnosis was confirmed postoperatively by histopathological examination.

Complications were recorded and graded according to the Clavien-Dindo (CD) classification [32]. The highest grade was registered for each patient and CD grade IV was evaluated in further analysis. Morbidity was defined as the occurrence of a complication during the initial hospital stay or within 90 postoperative days. It included bile leakage, post-hepatectomy hemorrhage and PHLF all defined as proposed by the International Study Group of Liver Surgery (ISGLS) [39-41], wound infection, wound healing disorder, wound dehiscence, intra-abdominal 
infection, liver abscess, cholangitis, urinary tract infection, central line infection, sepsis, atelectasis, pneumonia, pleural effusion, pleural empyema, pulmonary embolism, respiratory decompensation, multiple organ failure, myocardial infarction, cardiac arrhythmia, acute renal failure, gastrointestinal bleeding, and thrombotic complications. Unplanned readmission was defined as readmission to any hospital within 90 days after discharge due to a complication related to surgery.

\section{Endpoints}

The primary endpoint of the study was the 90-day mortality. Secondary endpoints were 30-day mortality, morbidity, Clavien-Dindo grade IV complications, unplanned readmissions, bile leakage, post-hepatectomy hemorrhage and post-hepatectomy liver failure (PHLF). Short-term outcome encompassed these endpoints. Exposure variables were diabetes mellitus, obesity and overweight.

\section{Statistics}

Statistical analysis was performed using the software $\mathrm{R}$ (Version 3.2.2) [42]. Univariate analysis was performed using Pearson's chi-square test with Yates' continuity correction. Two-tailed Fisher's exact test was used instead when the expected cell count in any cell of the chi-square test was below five. Normal weight was used as reference for overweight and obesity. Multivariate analysis using logistic regression was carried out to assess whether diabetes mellitus, overweight, and obesity were independent predictors of a worse short-term outcome. Preoperative and operative characteristics that were significant for mortality in univariate analysis were chosen as covariates (data not shown). With this approach the following variables were included: Age of 60 years or more at the day of surgery, male gender, arterial hypertension, chronic renal failure, preoperative chemotherapy, right trisectionectomy, left trisectionectomy, biliodigestive anastomosis, benign indication, colorectal liver metastasis (CRLM) and cholangiocarcinoma. The results of the multivariate analysis were expressed as odds ratio (OR) and 95\% confidence interval $(95 \% \mathrm{CI})$. A p-value $\leq 0.05$ was considered significant.

\section{Results}

The database included 1619 liver resections, 565 of which were major liver resections. After applying the exclusion criteria 417 patients were included into the analysis. The participant flow diagram is depicted in Fig. 1.

The preoperative patient characteristics, surgical procedures, and histopathological results as well as their associations with diabetes are summarized in Table 1 and their associations with overweight, and obesity are summarized in Table 2. Patients with diabetes had more frequently an age $\geq 60$ years, male gender, ASA classification $\geq$ III, arterial hypertension, and hepatocellular carcinoma than non-diabetics (p-values $<0.0001,0.003$, $0.001,<0.0001$, and 0.01 , respectively). Diabetics were less likely to receive preoperative chemotherapy and to be operated for CRLM (p-values 0.01 and 0.03 , respectively). Patients with overweight were more frequently male and had higher rates of arterial hypertension and liver steatosis of $\geq 5 \%$ than patients without overweight (p-values $0.04,0.0002$, and 0.004 , respectively). Obese patients were more likely to have arterial hypertension, cardiac failure, and liver steatosis of $\geq 5 \%$ than nonobese patients ( $p$-values $<0.0001,0.01$, and $<0.0001$, respectively). Neither overweight nor obesity were associated with a special tumor type or with diabetes mellitus. Diabetes mellitus was not associated with overweight or obesity.

In univariate analysis Diabetes mellitus was associated with significantly higher rates of 30- and 90-day mortality, morbidity, CD grade IV, and PHLF (p-values $0.02,0.03,0.01,0.0004$, and 0.01 , respectively). In addition, diabetic patients had significantly higher rates of wound healing disorders (35.7\% in diabetics versus $20 \%$ in non-diabetics, $\mathrm{p}=0.01)$, pneumonia $(17.9 \%$ vs. $8.4 \%$, $\mathrm{p}=0.048)$, pleural effusion ( $35.7 \%$ vs. $16.7 \%, \mathrm{p}=0.002)$, respiratory decompensation $(25 \%$ vs. $5.7 \%, \mathrm{p}<0.0001)$, acute renal failure $(25 \%$ vs. $7.2 \%, \mathrm{p}<0.0001)$, and gastrointestinal bleeding $(8.9 \%$ vs. $1.2 \%, \mathrm{p}=0.004)$. Overall 30- and 90-day mortality after major resection was $6.1 \%(\mathrm{n}=25)$ and $11.8 \%(\mathrm{n}=47)$, respectively, and overall-morbidity rate including $\mathrm{CD}$ I to $\mathrm{V}$ complications was $59.8 \%$ (234 patients). Complications of $\mathrm{CD}$ grade IV occurred in $10.1 \%(\mathrm{n}=42)$ of patients, and $19.7 \%(n=68)$ of patients had unplanned readmissions. Bile leakage ISGLS Grade A to C was recorded in 23.8\% $(\mathrm{n}=93)$, post-hepatectomy hemorrhage ISGLS Grade A to $\mathrm{C}$ in $5.1 \%(\mathrm{n}=20)$ and PHLF ISGLS Grade A to C in $18.2 \%(\mathrm{n}=71)$.

Table 3 shows the results of the multivariate analysis. Diabetes mellitus was an independent predictor of higher rates of morbidity $(\mathrm{OR}=2.44, \mathrm{p}=0.02)$, $\mathrm{CD}$ grade IV complications $(\mathrm{OR}=3.6, \mathrm{p}=0.004)$, unplanned readmissions $(\mathrm{OR}=2.44, \mathrm{p}=0.04)$, and bile leakage $(O R=2.06, p=0.046)$. The influence of diabetes mellitus on 30- and 90-day mortality and PHLF could not be confirmed in multivariate analysis. In accordance with univariate analysis, neither overweight nor obesity were associated with any of the outcome variables. The results of the multivariate analysis for the other independent variables are shown in the Additional file 1: Table S1. 


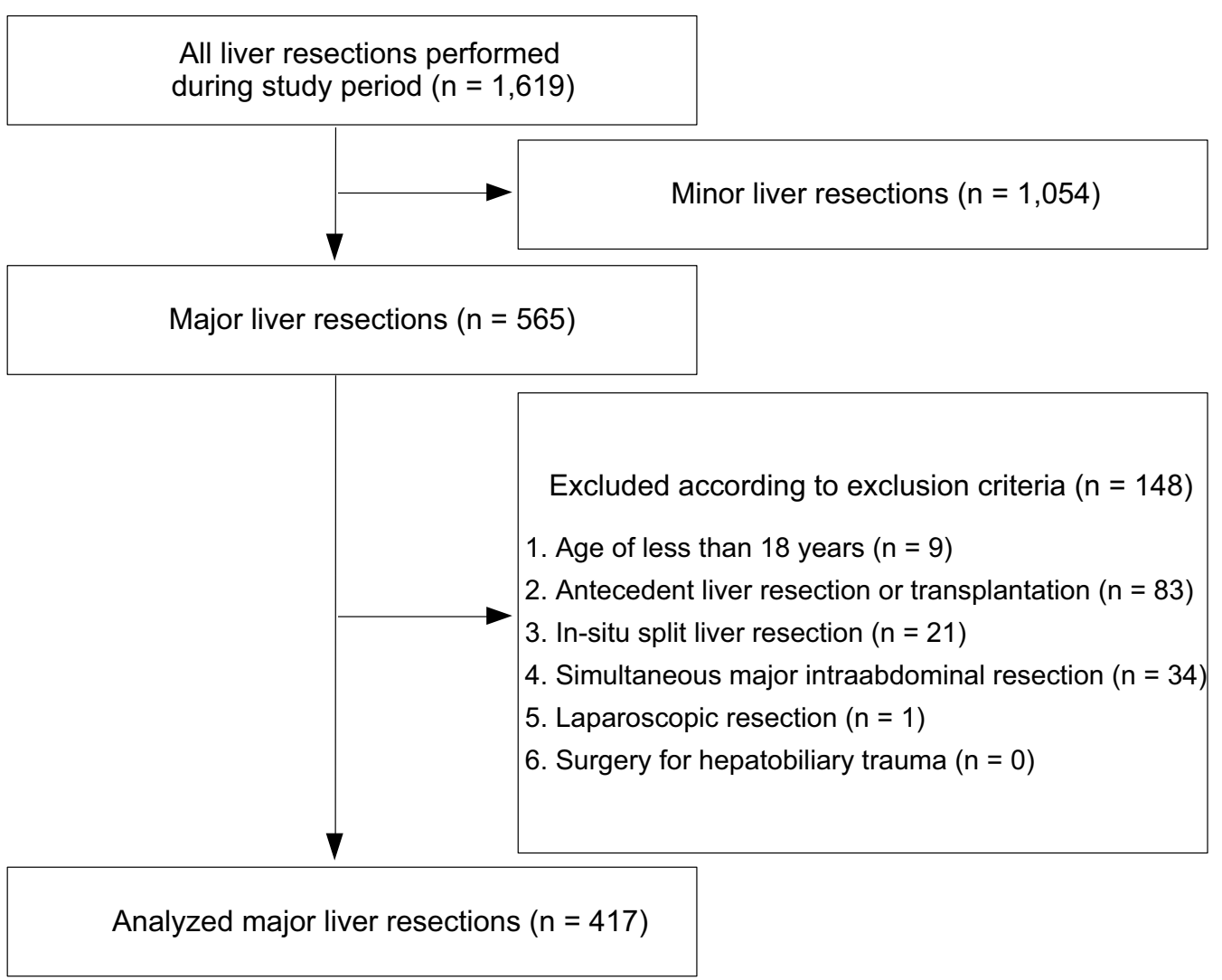

Fig. 1 Participant flow diagram showing the patient selection process

\section{Discussion}

It is discussed controversially, whether diabetes mellitus, obesity, and overweight are major risk factors for the short-term outcome after liver resection. The present study analyzed the patient population of a tertiary referral center with a high caseload of complex major liver resections.

Diabetes mellitus was found to independently predict a complicated postoperative course including significantly higher rates of morbidity, major complications, unplanned readmissions, and bile leakages, but it was not independently associated with a higher mortality rate. The present results are supported by the meta-analysis of Li et al., which showed higher rates of postoperative morbidity, liver failure, and infectious complications in diabetic patients [43]. Their study did not differentiate between major and minor resections, however. Few studies have analyzed the risk of diabetic patients after major liver resection previously. They reported heterogeneous results and often included only one histopathological entity. The results of Poon et al. in patients with hepatocellular carcinoma support the findings of the present analysis: diabetic patients did not have an increased risk for mortality after major resection [31]. In contrast,
Little et al., showed different results for patients undergoing liver resection for CRLM. They found that diabetes went along with a higher mortality and no higher morbidity [30]. However, the comparability to the present study might be limited because in the study of Little et al., all diabetic patients that died after major liver resection had received neo-adjuvant chemotherapy. Balzan et al. analyzed the impact of overweight on the outcome after hepatectomy. Diabetes was not an independent predictor of major postoperative complications, but a detailed subgroup analysis for diabetic patients was not included [33]. In consideration of the present findings, diabetic patients should be informed about a higher risk of a complicated postoperative course, which warrants increased alertness and an experienced postoperative care setting. Nevertheless, as diabetes mellitus was not an independent predictor of mortality, these patients should not be denied major liver resection. Given the results of Little et al. even higher precaution might be necessary for patients with diabetes, that received preoperative chemotherapy.

In contrast to the higher risk of patients with diabetes, the present study found no higher mortality and morbidity rates in patients with obesity or overweight. These results are supported by the findings of Mathur et al. 
Table 1 Preoperative patients characteristics, surgical procedures, and histopathological results in association with diabetes mellitus

\begin{tabular}{|c|c|c|c|}
\hline & \multirow{2}{*}{$\begin{array}{l}\text { Study population } \\
\mathrm{n} / \mathrm{N}(\%) \text { or mean } \pm \text { standard deviation }\end{array}$} & \multicolumn{2}{|c|}{ Diabetes mellitus } \\
\hline & & n (\%) & $\mathrm{p}$ \\
\hline Total & $417 / 417(100)$ & $59(14.1)$ & \\
\hline \multicolumn{4}{|l|}{ Pre-operative patient characteristics } \\
\hline Body mass index $\left(\mathrm{kg} / \mathrm{m}^{2}\right), \mathrm{n}=414$ & $25.2 \pm 4.1$ & & \\
\hline Underweight & 15/414 (3.6) & $2(3.4)$ & 1 \\
\hline Normal weight & 204/414 (49.3) & $22(37.9)$ & 0.09 \\
\hline Overweight & $147 / 414(35.5)$ & $27(46.6)$ & 0.08 \\
\hline Obesity & 48/414 (11.6) & $7(12.1)$ & 1 \\
\hline Morbid obesity & $9 / 414(2.2)$ & $1(1.7)$ & 1 \\
\hline Age (years), $n=417$ & $59.1 \pm 13.4$ & & \\
\hline Age $\geq 60$ years & 226/417 (54.2) & $48(81.4)$ & $<0.0001$ \\
\hline Male gender & 232/417 (55.6) & $44(74.6)$ & 0.003 \\
\hline ASA classification, $n=410$ & $2.4 \pm 0.6$ & & \\
\hline ASA III classification or more & 192/410 (46.8) & $39(67.2)$ & 0.001 \\
\hline \multicolumn{4}{|l|}{ Pre-existing disease } \\
\hline Arterial hypertension & $184 / 417(44.1)$ & $50(84.7)$ & $<0.0001$ \\
\hline Cardiac failure & $7 / 417(1.7)$ & $3(5.1)$ & 0.06 \\
\hline Chronic renal failure & $16 / 417(3.8)$ & $3(5.1)$ & 0.48 \\
\hline Lung disease & $33 / 417(7.9)$ & $3(5.1)$ & 0.6 \\
\hline Hepatitis B or C & $18 / 417(4.3)$ & $1(1.7)$ & 0.49 \\
\hline Esophageal varices & $4 / 417(1)$ & $0(0)$ & 1 \\
\hline Regular alcohol consumption & $28 / 417(6.7)$ & $4(6.8)$ & 1 \\
\hline Nicotine abuse & $69 / 417(16.5)$ & $8(13.6)$ & 0.63 \\
\hline \multicolumn{4}{|l|}{ Pre-operative treatment } \\
\hline Chemotherapy & $106 / 417(25.4)$ & $6(10.2)$ & 0.01 \\
\hline Chemoembolization & $11 / 417(2.6)$ & $0(0)$ & 0.38 \\
\hline Portal vein embolization & $12 / 417(2.9)$ & $4(6.8)$ & 0.07 \\
\hline \multicolumn{4}{|l|}{ Laboratory values } \\
\hline International normalized ratio $>1.2$ & $11 / 416(2.6)$ & $1(1.7)$ & 1 \\
\hline Total bilirubin $>1$ mg/dl & $80 / 411(19.5)$ & $13(22.4)$ & 0.66 \\
\hline \multicolumn{4}{|l|}{ Characteristics of surgery } \\
\hline \multicolumn{4}{|l|}{ Extent of surgery } \\
\hline Right hemihepatectomy & $226 / 417(54.2)$ & $31(52.5)$ & 0.89 \\
\hline Left hemihepatectomy & $90 / 417(21.6)$ & $13(22)$ & 1 \\
\hline Right trisectionectomy & $56 / 417(13.4)$ & $7(11.9)$ & 0.86 \\
\hline Left trisectionectomy & $27 / 417(6.5)$ & $6(10.2)$ & 0.25 \\
\hline Segmental resection* & $18 / 417(4.3)$ & $2(3.4)$ & 1 \\
\hline Adrenalectomy & $12 / 417(2.9)$ & $0(0)$ & 0.23 \\
\hline Biliodigestive anastomosis & $107 / 417(25.7)$ & $16(27.1)$ & 0.91 \\
\hline \multicolumn{4}{|l|}{ Resection device / technique } \\
\hline Stapler & 299/406 (73.6) & $46(83.6)$ & 0.1 \\
\hline Ligasure & $34 / 406(8.4)$ & $3(5.5)$ & 0.6 \\
\hline Clamp-crushing technique & $35 / 406(8.6)$ & $2(3.6)$ & 0.2 \\
\hline Cavitron Ultrasonic Surgical Aspirator & $32 / 406(7.9)$ & $4(7.3)$ & 1 \\
\hline Others & $6 / 406(1.5)$ & $0(0)$ & 1 \\
\hline Pringle maneuver & $88 / 411(21.4)$ & $12(21.1)$ & 1 \\
\hline Operative time (min), $n=410$ & $237.7 \pm 110$ & & \\
\hline Blood loss $\geq 1000 \mathrm{ml}, \mathrm{n}=409$ & $148 / 409(36.2)$ & $26(44.8)$ & 0.18 \\
\hline
\end{tabular}


Table 1 (continued)

\begin{tabular}{|c|c|c|c|}
\hline & \multirow{2}{*}{$\begin{array}{l}\text { Study population } \\
\mathrm{n} / \mathrm{N}(\%) \text { or mean } \pm \text { standard deviation }\end{array}$} & \multicolumn{2}{|c|}{ Diabetes mellitus } \\
\hline & & n (\%) & $p$ \\
\hline Transfusion of packed red blood cells & $148 / 417(35.5)$ & $28(47.5)$ & 0.054 \\
\hline \multicolumn{4}{|l|}{ Characteristics of histopathology } \\
\hline Non-malignant indication & $57 / 417(13.7)$ & $3(5.1)$ & - \\
\hline Living liver donation & $8 / 417(1.9)$ & $0(0)$ & 0.61 \\
\hline Malignant indication & $360 / 417(86.3)$ & $56(94.9)$ & 0.06 \\
\hline Colorectal liver metastasis & $123 / 417(29.5)$ & $10(16.9)$ & 0.03 \\
\hline Other liver metastases & $56 / 417(13.4)$ & $9(15.3)$ & 0.81 \\
\hline Cholangiocarcinoma & $136 / 417(32.6)$ & $25(42.4)$ & 0.12 \\
\hline Hepatocellular carcinoma & $37 / 417(8.9)$ & $11(18.6)$ & 0.01 \\
\hline Other malignant tumor & $8 / 417(1.9)$ & $1(1.7)$ & 1 \\
\hline Tumor diameter $>2.5 \mathrm{~cm}$ & 268/369 (72.6) & $45(81.8)$ & 0.14 \\
\hline Liver cirrhosis & 15/417 (3.6) & $4(6.8)$ & 0.25 \\
\hline Liver steatosis $\geq 5 \%$ & $155 / 417(37.2)$ & $28(47.5)$ & 0.11 \\
\hline
\end{tabular}

Bold values represent statistically significant results ( $p$-values $<0.05$ )

ASA American Society of Anesthesiologists. Binary variables are given as frequency (proportion) in all columns except for the column 'Study population' where the number of patients without missing data for this variable is given additionally. Continuous variables are given as mean \pm standard deviation

${ }^{*} \geq 3$ segments not classified by formal terms such as hemihepatectomy or trisectionectomy

[44] and Viganò et al. [26], who showed no independent association of obesity and overweight with mortality and morbidity after major liver resection. However, there are heterogeneous reports in the literature. An increased risk for major complications after major resections was reported in obese and overweight patients previously $[24,33]$. Since mortality rates were not increased in those reports, this should not be considered a limitation for surgery [33]. The study of Zogg et al. found only morbid obesity to be associated with higher mortality and morbidity rates, while non-morbid obesity and overweight were no risk factors [25]. Similarly, the meta-analysis of Rong et al. on liver resection for HCC found no association between BMI and mortality [45]. In accordance with the findings of the present study, there is no reason to deprive overweight patients of major liver resections. Nevertheless, the subgroup of morbidly obese patients should be assessed with special attention.

The current study found diabetes to be associated with several individual complications. The most notable were bile leakage, pneumonia, respiratory insufficiency, acute renal failure, and gastrointestinal bleeding, which are potentially life-threatening $[46,47]$ and thus correspond to the higher rate of $\mathrm{CD}$ grade IV complications. The findings are supported by previous studies that found diabetics to suffer more frequently from infectious [48] and pulmonary [49] complications, and acute renal failure $[27,50,51]$ after liver resection. They are in line with the detrimental effect of diabetes mellitus on immunological [52-54] and renal function [55]. The higher rates of bile leakage in diabetic patients are more difficult to understand. Potentially, the diabetic affection of the microcirculation [56] provoked biliary transudation and impaired healing at the resection surface.

Major liver resection is still associated with relevantly higher rates of complications and mortality than minor liver resection $[8,10,11,57]$. In the present study, PHLF occurred in $18.2 \%$ of patients. Two recent studies on major liver resection that also applied the ISGLS definition found a PHLF rate of 9.6-30.1\% [58, 59]. In the present cohort, 90 -day mortality was $11.8 \%$. This is within the numbers reported from hepatobiliary centers all over Germany [57]. While the analysis of major resections for CRLM showed 90-day mortality rates between 2 and 8\% [60-63], 90-day mortality rates for perihilar cholangiocarcinoma of up to $14 \%$ [64] and up to $18 \%$ for HCCs have been reported [65]. Furthermore, plain major resections such as hemi-hepatectomies show a better outcome than extended liver resections $[35,62,66]$. In extended liver resections a 90 -day mortality rate of up to $16.7 \%$ has been reported $[67,68]$.

The present study has some limitations. First, some diabetic, obese, or overweight patients might not have been presented to the surgeons as candidates for resection as their treating doctors might have considered them at high risk for a fatal postoperative outcome. Nevertheless, the analysis showed that neither diabetic, obese nor overweight patients received different extents of surgery compared to non-diabetic and normal weight patients, respectively. Second, diabetic 
Table 2 Preoperative patients characteristics, surgical procedures, and histopathological results in association overweight, and obesity

\begin{tabular}{|c|c|c|c|c|c|c|}
\hline & Study population & Normal weight & Overweigh & & Obesity & \\
\hline & $\begin{array}{l}\mathrm{n} / \mathrm{N}(\%) \\
\text { or mean } \pm \text { standard } \\
\text { deviation }\end{array}$ & n (\%) & n (\%) & pt & n (\%) & $\mathrm{p} t$ \\
\hline Total & $417 / 417(100)$ & $204(49.3)$ & $147(35.5)$ & & $48(11.6)$ & \\
\hline Pre-operative patient characterist & & & & & & \\
\hline Diabetes mellitus & $59 / 417(14.1)$ & $22(10.8)$ & $27(18.4)$ & 0.06 & $7(14.6)$ & 0.62 \\
\hline Age (years), $n=417$ & $59.1 \pm 13.4$ & & & & & \\
\hline Age $\geq 60$ years & 226/417 (54.2) & $105(51.5)$ & $90(61.2)$ & 0.09 & $23(47.9)$ & 0.78 \\
\hline Male gender & 232/417 (55.6) & $108(52.9)$ & $95(64.6)$ & 0.04 & $26(54.2)$ & 1 \\
\hline ASA classification, $n=410$ & $2.4 \pm 0.6$ & & & & & \\
\hline ASA III classification or more & 192/410 (46.8) & $84(41.8)$ & $72(50.3)$ & 0.14 & $27(56.3)$ & 0.1 \\
\hline Pre-existing disease & & & & & & \\
\hline Arterial hypertension & $184 / 417(44.1)$ & $67(32.8)$ & $78(53.1)$ & 0.0002 & $33(68.8)$ & $<0.0001$ \\
\hline Cardiac failure & $7 / 417(1.7)$ & $1(0.5)$ & $2(1.4)$ & 0.57 & $4(8.3)$ & 0.01 \\
\hline Chronic renal failure & 16/417 (3.8) & $4(2)$ & $9(6.1)$ & 0.08 & $2(4.2)$ & 0.32 \\
\hline Lung disease & $33 / 417(7.9)$ & $13(6.4)$ & $12(8.2)$ & 0.66 & $4(8.3)$ & 0.54 \\
\hline Hepatitis B or C & $18 / 417(4.3)$ & $8(3.9)$ & $6(4.1)$ & 1 & $3(6.3)$ & 0.44 \\
\hline Esophageal varices & $4 / 417(1)$ & $3(1.5)$ & $1(0.7)$ & 0.64 & $0(0)$ & 1 \\
\hline Regular alcohol consumption & 28/417 (6.7) & $11(5.4)$ & $10(6.8)$ & 0.75 & $5(10.4)$ & 0.2 \\
\hline Nicotine abuse & $69 / 417(16.5)$ & $30(14.7)$ & $25(17)$ & 0.66 & $6(12.5)$ & 0.87 \\
\hline Pre-operative treatment & & & & & & \\
\hline Chemotherapy & $106 / 417(25.4)$ & $52(25.5)$ & $36(24.5)$ & 0.93 & $11(22.9)$ & 0.85 \\
\hline Chemoembolization & $11 / 417(2.6)$ & $7(3.4)$ & $3(2)$ & 0.53 & $1(2.1)$ & 1 \\
\hline Portal vein embolization & $12 / 417(2.9)$ & $10(4.9)$ & $2(1.4)$ & 0.13 & $0(0)$ & 0.22 \\
\hline Laboratory values & & & & & & \\
\hline $\mathrm{INR}>1.2$ & $11 / 416(2.6)$ & $7(3.4)$ & $3(2)$ & 0.53 & $0(0)$ & 0.35 \\
\hline Total bilirubin > 1 mg/dl & 80/411 (19.5) & $43(21.3)$ & $28(19.3)$ & 0.75 & $6(12.8)$ & 0.26 \\
\hline Characteristics of surgery & & & & & & \\
\hline Extent of surgery & & & & & & \\
\hline Right hemihepatectomy & 226/417 (54.2) & $110(53.9)$ & $77(52.4)$ & 0.86 & $25(52.1)$ & 0.95 \\
\hline Left hemihepatectomy & $90 / 417(21.6)$ & $43(21.1)$ & $34(23.1)$ & 0.74 & $12(25)$ & 0.69 \\
\hline Right trisectionectomy & $56 / 417(13.4)$ & $31(15.2)$ & $17(11.6)$ & 0.41 & $6(12.5)$ & 0.8 \\
\hline Left trisectionectomy & $27 / 417(6.5)$ & $13(6.4)$ & $10(6.8)$ & 1 & $4(8.3)$ & 0.54 \\
\hline Segment resection* & $18 / 417(4.3)$ & $7(3.4)$ & $9(6.1)$ & 0.35 & $1(2.1)$ & 1 \\
\hline Adrenalectomy & & $5(2.5)$ & $3(2)$ & 1 & $4(8.3)$ & 0.07 \\
\hline Biliodigestive anastomosis & & $55(27)$ & $41(27.9)$ & 0.94 & $8(16.7)$ & 0.19 \\
\hline Resection device / technique & & & & & & \\
\hline Stapler & & $142(72.1)$ & $108(74.5)$ & 0.71 & $35(76.1)$ & 0.71 \\
\hline Ligasure & & $20(10.2)$ & $10(6.9)$ & 0.39 & $2(4.3)$ & 0.27 \\
\hline Clamp-crushing technique & & $14(7.1)$ & $15(10.3)$ & 0.39 & $6(13)$ & 0.23 \\
\hline CUSA & & $17(8.6)$ & $10(6.9)$ & 0.71 & $3(6.5)$ & 0.77 \\
\hline Others & & $4(2)$ & $2(1.4)$ & 1 & $0(0)$ & 1 \\
\hline Pringle maneuver & & $41(20.5)$ & $30(20.5)$ & 1 & $11(23.4)$ & 0.81 \\
\hline Operative time $(\min ), n=410$ & & & & & & \\
\hline Blood loss $\geq 1000 \mathrm{ml}, \mathrm{n}=409$ & & $74(37)$ & $59(41.3)$ & 0.49 & $11(22.9)$ & 0.09 \\
\hline Transfusion of pRBC & & $70(34.3)$ & $57(38.8)$ & 0.46 & $15(31.3)$ & 0.81 \\
\hline Characteristics of histopathology & & & & & & \\
\hline Non-malignant indication & & $27(13.2)$ & 19 (12.9) & - & $5(10.4)$ & - \\
\hline Living liver donation & & $5(2.5)$ & $3(2)$ & 1 & $0(0)$ & 0.59 \\
\hline
\end{tabular}


Table 2 (continued)

\begin{tabular}{|c|c|c|c|c|c|c|}
\hline & \multirow{2}{*}{$\begin{array}{l}\text { Study population } \\
\mathrm{n} / \mathrm{N}(\%) \\
\text { or mean } \pm \text { standard } \\
\text { deviation }\end{array}$} & \multirow{2}{*}{$\begin{array}{l}\text { Normal weight } \\
\text { n (\%) }\end{array}$} & \multicolumn{2}{|c|}{ Overweight } & \multicolumn{2}{|l|}{ Obesity } \\
\hline & & & n (\%) & $\mathrm{p}+$ & n (\%) & $\mathrm{p} \dagger$ \\
\hline Malignant indication & & $177(86.8)$ & $128(87.1)$ & 1 & $43(89.6)$ & 0.77 \\
\hline Colorectal liver metastasis & & $53(26)$ & $46(31.3)$ & 0.33 & $18(37.5)$ & 0.16 \\
\hline Other liver metastases & & $33(16.2)$ & $18(12.2)$ & 0.38 & $3(6.3)$ & 0.12 \\
\hline Cholangiocarcinoma & & 65 (31.9) & $51(34.7)$ & 0.66 & $18(37.5)$ & 0.56 \\
\hline Hepatocellular carcinoma & & $22(10.8)$ & $10(6.8)$ & 0.28 & $3(6.3)$ & 0.43 \\
\hline Other malignant tumor & & $4(2)$ & $3(2)$ & 1 & $1(2.1)$ & 1 \\
\hline Tumor diameter $>2.5 \mathrm{~cm}$ & & $129(71.7)$ & $92(71.3)$ & 1 & $37(78.7)$ & 0.43 \\
\hline Liver cirrhosis & & $8(3.9)$ & $4(2.7)$ & 0.75 & $3(6.3)$ & 0.44 \\
\hline Liver steatosis $\geq 5 \%$ & & $55(27)$ & $62(42.2)$ & 0.004 & $35(72.9)$ & $<0.0001$ \\
\hline
\end{tabular}

Bold values represent statistically significant results ( $p$-values $<0.05$ )

†Normal weight was used as reference for overweight and obesity. Underweight is not shown due to the low number of patients ( $\mathrm{n}=15$ ). ASA American Society of Anesthesiologists, INR International normalized ratio, CUSA Cavitron Ultrasonic Surgical Aspirator, pRBC packed red blood cells. Binary variables are given as frequency (proportion) in all columns except for the column 'Study population' where the number of patients without missing data for this variable is given additionally.

Continuous variables are given as mean \pm standard deviation

* $\geq 3$ segments not classified by formal terms such as hemihepatectomy or trisectionectomy

Table 3 Multivariate analysis of association of preoperative diabetes mellitus, overweight, and obesity with postoperative outcome variables

\begin{tabular}{|c|c|c|c|c|c|c|c|}
\hline & \multirow[b]{2}{*}{$\mathrm{n}$} & \multicolumn{2}{|c|}{ Diabetes mellitus } & \multicolumn{2}{|l|}{ Overweight } & \multirow{2}{*}{$\begin{array}{l}\text { Obesity } \\
\text { OR }(95 \% \mathrm{Cl})\end{array}$} & \multirow[b]{2}{*}{$\mathrm{p}$} \\
\hline & & OR $(95 \% \mathrm{Cl})$ & $\mathbf{p}$ & OR $(95 \% \mathrm{Cl})$ & $\mathrm{p}$ & & \\
\hline 30-day mortality & 405 & $1.82(0.6 ; 5.47)$ & 0.29 & $0.36(0.12 ; 1.08)$ & 0.07 & $0.47(0.09 ; 2.49)$ & 0.38 \\
\hline 90-day mortality & 395 & $1.22(0.5 ; 2.95)$ & 0.66 & $0.85(0.39 ; 1.86)$ & 0.69 & $0.48(0.12 ; 1.94)$ & 0.3 \\
\hline Morbidity & 389 & $2.44(1.15 ; 5.19)$ & 0.02 & $1.46(0.87 ; 2.43)$ & 0.15 & $1.06(0.49 ; 2.28)$ & 0.89 \\
\hline Clavien-Dindo grade IV & 414 & $3.6(1.49 ; 8.66)$ & 0.004 & $1.56(0.73 ; 3.35)$ & 0.25 & $1.76(0.58 ; 5.36)$ & 0.32 \\
\hline Unplanned readmission rate & 342 & $2.44(1.03 ; 5.78)$ & 0.04 & $1(0.53 ; 1.87)$ & 0.99 & $1.07(0.41 ; 2.76)$ & 0.89 \\
\hline Bile leakage & 389 & $2.06(1.01 ; 4.21)$ & 0.046 & $1.42(0.8 ; 2.5)$ & 0.23 & $1.46(0.62 ; 3.41)$ & 0.38 \\
\hline Posthepatectomy haemorrhage & 389 & $0.73(0.17 ; 3.03)$ & 0.66 & $1.4(0.5 ; 3.93)$ & 0.52 & $1.98(0.44 ; 8.94)$ & 0.38 \\
\hline Posthepatectomy liver failure & 389 & $1.76(0.81 ; 3.82)$ & 0.15 & $1.63(0.86 ; 3.11)$ & 0.13 & $0.54(0.16 ; 1.82)$ & 0.32 \\
\hline
\end{tabular}

Bold values represent statistically significant results ( $p$-values $<0.05$ )

OR odds ratio, $95 \%$ Cl 95\% confidence interval. Results for the following model variables are shown in the supplementary appendix: underweight, age $\geq 60$ years, male gender, arterial hypertension, chronic renal failure, preoperative chemotherapy, extended right hemihepatectomy, extended left hemihepatectomy, biliodigestive anastomosis, benign indication, colorectal liver metastasis and cholangiocarcinoma. The endpoints bile leakage, post-hepatectomy haemorrhage and posthepatectomy liver failure were defined as proposed by the International Study Group of Liver Surgery [27-29]

patients less frequently underwent preoperative chemotherapy than non-diabetics. However, this was probably partly secondary to a significantly lower rate of CRLM among diabetic patients as the majority (i.e. $71.7 \%$ ) of patients with preoperative chemotherapy had CRLM. Third, since the cohort included only patients from a European center the outcome might not be comparable with Asian cohorts where the BMI of diabetic patients is often normal and there has been not such a tremendous increase in the average BMI of the population [69].

\section{Conclusions}

Diabetes mellitus is an independent risk factor for a complicated postoperative course after major liver resection with significantly higher rates of morbidity, major complications, unplanned readmissions, and bile leakages. However, it was not associated with a higher mortality rate. Individual patient counselling should be intensified for diabetics before major liver resection and extended resections should be performed in an experienced tertiary care center. In contrast, the data suggest obese and overweight patients to be safe to undergo major liver 
resection as they had no significantly increased postoperative mortality nor morbidity.

\section{Supplementary information}

Supplementary information accompanies this paper at https://doi. org/10.1186/s12893-020-00971-w.

Additional file 1: Table S1. Multivariate logistic regression analysis of association of preoperative variables with postoperative outcome variables.

\section{Abbreviations}

BMI: Body Mass Index; CD: Clavien-Dindo Classification of surgical complications; Cl: Confidence Interval; CRLM: Colorectal liver metastasis; CUSA: Cavitron ultrasonic aspirator; ISGLS: International Study Group of Liver Surgery; NAFLD: Non-alcoholic fatty liver disease; OR: Odds ratio; PHLF: Posthepatectomy liver failure; WHO: World Health Organization.

\section{Acknowledgments}

Established resources, facilities, and organisational structures at the University Hospital of Heidelberg were used during the conduction process. Alexander Fischer and Juri Fuchs share first-authorship for this article

\section{Authors' contributions}

$\mathrm{AF}$, JF and $\mathrm{KH}$ conceived and designed the study. AF and UH collected the data. AF, JF, UH and $\mathrm{KH}$ analyzed the data. AF, JF and $\mathrm{KH}$ wrote the manuscript. $A F, J F$ and $K H$ performed the literature search, prepared data analyses and edited the manuscript in parts. AF, JF, CS, UH, AB, AM, MB and $\mathrm{KH}$ reviewed and edited the manuscript. All authors read and approved the manuscript.

\section{Funding}

Open Access funding enabled and organized by Projekt DEAL. This study received no external funding.

\section{Availability of data and materials}

Results of all multivariate analyses, which were performed in our study, are either presented in the manuscript or attached as supplementary material. All other data used for this study are presented in the tables attached.

\section{Ethics approval and consent to participate}

The institutional review board of the Medical Faculty of the University of Heidelberg agreed to the data collection and conduct the present study (07/2013). As data for the database was entered anonymized, no additiona patient consent was necessary (Sect. 15, paragraph 1 of the code of medical ethics of the federal state of Baden-Württemberg).

\section{Consent for publication}

Not applicable.

\section{Competing interests}

All authors declare that they have no competing interests that could have compromised the outcome of the trial.

\section{Author details}

${ }^{1}$ Department of General and Transplant Surgery, University Hospital Heidelberg, Ruprecht-Karls-University, Im Neuenheimer Feld 110, 69120 Heidelberg Germany. ${ }^{2}$ Department of General and Visceral Surgery, Municipal Hospital Karlsruhe, Moltkestrasse 90, 76133 Karlsruhe, Germany.

Received: 14 June 2020 Accepted: 18 November 2020 Published online: 30 November 2020

\section{References}

1. Dimick JB, et al. National trends in the use and outcomes of hepatic resection. J Am Coll Surg. 2004;199(1):31-8.
2. Hoffmann $\mathrm{K}$, et al. Is hepatic resection for non-colorectal, non-neuroendocrine liver metastases justified? Ann Surg Oncol. 2015a;22(3):1083-92.

3. Hoffmann $\mathrm{K}$, et al. Impact of portal vein resection on oncologic longterm outcome in patients with hilar cholangiocarcinoma. Surgery. 2015b;158(5):1252-60.

4. Lyratzopoulos $\mathrm{G}$, et al. Recent trends in liver resection surgery activity and population utilization rates in English regions. HPB. 2007;9(4):277-80.

5. McColl RJ, et al. Recent trends of hepatic resection in Canada: 1995-2004. J Gastrointest Surg. 2008;12(11):1839.

6. Adam R, Kitano Y. Multidisciplinary approach of liver metastases from colorectal cancer. Ann Gastroenterol Surg. 2019;3(1):50-6.

7. Dokmak S, et al. 2012 Liver resections in the 21 st century: we are far from zero mortality. HPB. 2013;15(11):908-15.

8. Farges $\mathrm{O}$, et al. Incidence and risks of liver resection: an all-inclusive French nationwide study. Ann Surg. 2012;256(5):697-705.

9. Riediger C, et al. Comparative analysis of different transection techniques in minor and major hepatic resections: a prospective cohort study. Int J Surg. 2013;11(9):826-33.

10. Nanashima A, et al. Comparative analysis of postoperative morbidity according to type and extent of hepatectomy. Hepatogastroenterology. 2005;52(63):844-8.

11. Vibert $E$, et al. Actual incidence and long-term consequences of posthepatectomy liver failure after hepatectomy for colorectal liver metastases. Surgery. 2014;155(1):94-105.

12. Cho N, et al. IDF Diabetes Atlas: global estimates of diabetes prevalence for 2017 and projections for 2045. Diabetes Res Clin Pract. 2018:138:271-81.

13. $\mathrm{Ng} \mathrm{M}$, et al. Global, regional, and national prevalence of overweight and obesity in children and adults during 1980-2013: a systematic analysis for the Global Burden of Disease Study 2013. Lancet. 2014;384(9945):766-81.

14. International Diabetes Federation. IDF Diabetes Atlas, 8 ed. 2017. http:// www.diabetesatlas.org. Accessed 1 Oct 2019.

15. World Health Organization. Global Health Observatory Data Repository. Noncommunicable diseases, risk factors, overweight / obesity: obesity (body massindex $>=30$ ) (crude estimate). 2016. http://apps.who.int/ gho/data/node.main.A900C?lang=en. Accessed 1 Oct 2019.

16. Younossi ZM, et al. Global epidemiology of nonalcoholic fatty liver disease - meta-analytic assessment of prevalence, incidence, and outcomes. Hepatology. 2016;64(1):73-84.

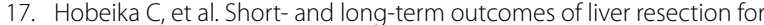
intrahepatic cholangiocarcinoma associated with the metabolic syndrome. World J Surg. 2019;43(8):2048-60.

18. Angulo $P$, et al. Independent predictors of liver fibrosis in patients with nonalcoholic steatohepatitis. Hepatology. 1999;30(6):1356-62.

19. Younossi ZM, et al. Nonalcoholic fatty liver disease in patients with type 2 diabetes. Clin Gastroenterol Hepatol. 2004;2(3):262-5.

20. De Meijer $\vee$, et al. Systematic review and meta-analysis of steatosis as a risk factor in major hepatic resection. Br J Surg. 2010;97(9):1331-9.

21. McCormack L, et al. Hepatic steatosis is a risk factor for postoperative complications after major hepatectomy: a matched case-control study. Ann Surg. 2007;245(6):923.

22. Reddy SK, et al. Underlying steatohepatitis, but not simple hepatic steatosis, increases morbidity after liver resection: a case-control study. Hepatology. 2012;56(6):2221-30.

23. Kurmann A, et al. Hepatic steatosis is associated with surgical-site infection after hepatic and colorectal surgery. Surgery. 2014;156(1):109-16.

24. Amini $\mathrm{N}$, et al. Liver regeneration after major liver hepatectomy: impact of body mass index. Surgery. 2016;160(1):81-91.

25. Zogg CK, et al. Influence of body mass index on outcomes after major resection for cancer. Surgery. 2015;158(2):472-85.

26. Viganò $L$, et al. Liver resection in obese patients: results of a case-control study. HPB. 2011;13(2):103-11.

27. Amptoulach S, Gross G, Kalaitzakis E. Differential impact of obesity and diabetes mellitus on survival after liver resection for colorectal cancer metastases. J Surg Res. 2015;199(2):378-85.

28. Guo Z, et al. Obesity does not influence outcomes in hepatocellular carcinoma patients following curative hepatectomy. PLoS ONE. 2015;10(5):e0125649.

29. Wiggans $M$, et al. The interaction between diabetes, body mass index, hepatic steatosis, and risk of liver resection: insulin dependent diabetes is the greatest risk for major complications. HPB Surg. 2014. 2014. 
30. Little SA, et al. Diabetes is associated with increased perioperative mortality but equivalent long-term outcome after hepatic resection for colorectal cancer. J Gastrointest Surg. 2002;6(1):88-94.

31. Poon RT-P, Fan S-T, Wong J. Does diabetes mellitus influence the perioperative outcome or long term prognosis after resection of hepatocellular carcinoma? Am J Gastroenterol. 2002;97(6):1480-8.

32. Dindo D, Demartines N, Clavien P-A. Classification of surgical complications: a new proposal with evaluation in a cohort of 6336 patients and results of a survey. Ann Surg. 2004;240(2):205.

33. Balzan $\mathrm{S}$, et al. Safety of liver resections in obese and overweight patients. World J Surg. 2010;34(12):2960-8.

34. Egger ME, et al. Risk stratification for readmission after major hepatectomy: development of a readmission risk score. J Am Coll Surg. 2015;220(4):640-8.

35. Mayo SC, et al. Refining the definition of perioperative mortality following hepatectomy using death within 90 days as the standard criterion. HPB. 2011;13(7):473-82.

36. Strasberg S, et al. The Brisbane 2000 terminology of liver anatomy and resections. HPB. 2000;2(3):333-9.

37. Strasberg SM. Nomenclature of hepatic anatomy and resections: a review of the Brisbane 2000 system. J Hepato-Biliary-Pancreat Surg. 2005;12(5):351-5.

38. World Health Organization. Obesity: preventing and managing the global epidemic. 2000: World Health Organization.

39. Koch $M$, et al. Bile leakage after hepatobiliary and pancreatic surgery: a definition and grading of severity by the International Study Group of Liver Surgery. Surgery. 2011;149(5):680-8.

40. Rahbari NN, et al. Posthepatectomy liver failure: a definition and grading by the International Study Group of Liver Surgery (ISGLS). Surgery. 2011a;149(5):713-24.

41. Rahbari NN, et al. Post-hepatectomy haemorrhage: a definition and grading by the International Study Group of Liver Surgery (ISGLS). HPB. 2011b;13(8):528-35.

42. R Core Team, R: a language and environment for statistical computing. 2016.

43. Li Q, et al. Clinical outcomes of patients with and without diabetes mellitus after hepatectomy: a systematic review and meta-analysis. PLoS ONE. 2017:12(2):e0171129.

44. Mathur AK, et al. Body mass index and adverse perioperative outcomes following hepatic resection. J Gastrointest Surg. 2010;14(8):1285-91.

45. Rong $X$, et al. The association between body mass index and the prognosis and postoperative complications of hepatocellular carcinoma: a meta-analysis. Medicine. 2015;94(31):e1269.

46. Martin RC 2nd, Brennan MF, Jaques DP. Quality of complication reporting in the surgical literature. Ann Surg. 2002;235(6):803-13.

47. Ramacciato $\mathrm{G}$, et al. Hepatocellular carcinomas and primary liver tumors as predictive factors for postoperative mortality after liver resection: a meta-analysis of more than 35,000 hepatic resections. Am Surg. 2012;78(4):456-67.

48. Pessaux $P$, et al. Identification and validation of risk factors for postoperative infectious complications following hepatectomy. J Gastrointest Surg. 2013;17(11):1907-16.

49. Nobili C, et al. Multivariate analysis of risk factors for pulmonary complications after hepatic resection. Ann Surg. 2012;255(3):540-50.

50. Slankamenac K, et al. Development and validation of a prediction score for postoperative acute renal failure following liver resection. Ann Surg. 2009;250(5):720-8.

51. Tsai M-S, et al. Diabetes mellitus and increased postoperative risk of acute renal failure after hepatectomy for hepatocellular carcinoma: a nationwide population-based study. Ann Surg Oncol. 2014;21(12):3810-6.
52. McManus $L M$, et al. Agonist-dependent failure of neutrophil function in diabetes correlates with extent of hyperglycemia. J Leukoc Biol. 2001;70(3):395-404

53. Schindl $M$, et al. The value of residual liver volume as a predictor of hepatic dysfunction and infection after major liver resection. Gut. 2005;54(2):289-96.

54. Guo SA, DiPietro LA. Factors affecting wound healing. J Dent Res. 2010;89(3):219-29.

55. Narres $M$, et al. The incidence of end-stage renal disease in the diabetic (compared to the non-diabetic) population: a systematic review. PLoS ONE. 2016;11(1):e0147329.

56. Harrison SA, et al. Diabetic hepatosclerosis: diabetic microangiopathy of the liver. Arch Pathol Lab Med. 2006;130(1):27-32.

57. Filmann N, et al. Mortality after liver surgery in Germany. Br J Surg. 2019;106(11):1523-9.

58. Andreatos $\mathrm{N}$, et al. Albumin-bilirubin score: predicting short-term outcomes including bile leak and post-hepatectomy liver failure following hepatic resection. J Gastrointest Surg. 2017;21(2):238-48.

59. Herbert GS, et al. Early trends in serum phosphate and creatinine levels are associated with mortality following major hepatectomy. HPB. 2015;17(12):1058-65.

60. Idrees JJ, et al. Population level outcomes and costs of single stage colon and liver resection versus conventional two-stage approach for the resection of metastatic colorectal cancer. HPB. 2019;21(4):456-64.

61. Even Storli P, et al. Impact of increased resection rates and a liver parenchyma sparing strategy on long-term survival after surgery for colorectal liver metastases. A population-based study. Scand J Gastroenterol. 2019;54(7):890-8

62. Ubink I, et al. Surgical and oncologic outcomes after major liver surgery and extended hemihepatectomy for colorectal liver metastases. Clin Colorectal Cancer. 2016;15(4):e193-8.

63. Hosokawa I, et al. Outcomes of parenchyma-preserving hepatectomy and right hepatectomy for solitary small colorectal liver metastasis: a LiverMetSurvey study. Surgery. 2017;162(2):223-32.

64. Wiggers JK, et al. Postoperative mortality after liver resection for perihilar cholangiocarcinoma: development of a risk score and importance of biliary drainage of the future liver remnant. J Am Coll Surg. 2016;223(2):321331.e1.

65. Lim C, et al. Hepatectomy for hepatocellular carcinoma larger than $10 \mathrm{~cm}$ : preoperative risk stratification to prevent futile surgery. HPB. 2015;17(7):611-23.

66. Wei A, et al. Risk factors for perioperative morbidity and mortality after extended hepatectomy for hepatocellular carcinoma. Br J Surg. 2003;90(1):33-41.

67. Diggs $L$, et al. Income, education, insurance status and co-morbidities contribute to disparate perioperative mortality among patients undergoing major hepatic resections for liver cancer. HPB. 2019;21:S76.

68. Chan J, et al. Outcomes of central hepatectomy versus extended hepatectomy. Hepatobiliary Pancreat Dis Int. 2019;18(3):249-54.

69. Sone $\mathrm{H}$, et al. Obesity and type 2 diabetes in Japanese patients. Lancet. 2003:361(9351):85.

\section{Publisher's Note}

Springer Nature remains neutral with regard to jurisdictional claims in published maps and institutional affiliations. 